\title{
Determinants of $p 14 / A R F$ methylation in healthy females: association with reproductive and non-reproductive risk factors of breast cancer
}

\author{
Ghada M. Ezzat ${ }^{1^{*}}$ (D) and Mahmoud H. El-Shoeiby ${ }^{2}$
}

\begin{abstract}
Background: DNA methylation is associated with the risk factors of breast cancer. However, the impact of the reproductive and non-reproductive risk factors of breast cancer on p14/ARF methylation is not well known. Therefore, we investigated the relationships between $p 14 / A R F$ methylation percentage and risk factors of breast cancer including age, family history, obesity, and reproductive risk factors in 120 breast cancer-free subjects; 60 women with a firstdegree family history of breast cancer and 60 age-matched women with no family history of breast cancer. Extracted DNA from the whole blood was bisulfite-treated by EZ DNA modification kit. Quantitative methylation of p14/ARF was analyzed by methylation-specific PCR then methylation percentage of p14/ARF was calculated.

Results: P14/ARF methylation percentage was not related to any of the risk factors of breast cancer except age. Our study showed that $p 14 / A R F$ methylation percentage was significantly higher in females with age $\geq 40$ years than in females with age $<40$ years $(p=0.029)$. Also, a positive significant correlation between the $p 14 / A R F$ methylation percentage and age was detected $(r=0.285, p=0.014)$. Furthermore, univariate regression analysis showed that the age is independently associated with high $p 14 / A R F$ methylation percentage $(\beta=1.46, p=0.029)$.

Conclusion: Among healthy females, the age is strongly linked to the peripheral $p 14 / A R F$ methylation percentage. The present study suggests that $p 14 / A R F$ methylation is not associated with other breast cancer risk factors. These results need oncoming research on a large cohort to define the interactions between p14/ARF methylation and the risk factors of breast cancer.
\end{abstract}

\section{Background}

The $p 14$ gene located on human chromosome 9 (9p21) is a member of cyclin-D-dependent kinase (CDK) inhibitors that act as cell cycle regulators, such as $p 16$ and $p 15$ genes [1]. The cyclin-D-dependent kinase inhibitor 2A/inhibitor of cyclin-D4 (CDKN2A/INK4A) produces two proteins including $\mathrm{p} 16^{\mathrm{INK} 4 \mathrm{~A}}$ protein and $\mathrm{p} 14^{\mathrm{ARF}}$ (alternative reading frame protein) that are two alternative splicings [1]. P14/ARF is identified as a tumor suppressor gene, acts as an inhibitor of E3 ubiquitin ligase (MDM2), prevents the degradation of $\mathrm{p} 53$ by its attachment to the $\mathrm{p} 53 / \mathrm{MDM} 2$ complex [2], and so results in the arrest of the cell cycle. However,

\footnotetext{
* Correspondence: ghadaezzat20@gmail.com

${ }^{1}$ Department of Medical Biochemistry, Faculty of Medicine, Assiut University, Assiut 75151, Egypt

Full list of author information is available at the end of the article
}

the inhibitory effect of $p 14 / A R F$ on the cell cycle progression can extend to G1, G2/M phases, and cell apoptosis and can be done through either p53 or separately from it through interactions with other proteins that control cell cycle such as Tat-interactive protein, $60 \mathrm{kDa}$ (Tip60), nucleophosmin (NPM), transcription factor E2F, and (hypoxia-inducible factor1) HIF1alpha [3]. During carcinogenesis, the increase of p14/p53 expression induces cellular senescence and prevents the passage of cancer cells from G1 to $\mathrm{S}$ phase, and so, the sensitivity to chemotherapeutic agents increased [4]. Inactivation of p14/ARF gene due to genetic or epigenetic factors was reported to be associated with the growth of tumor cells $[5,6]$.

DNA methylation is the most common epigenetic changes and is usually associated with the repression of gene transcription [7]. It has been implicated in many 
biological cellular processes like apoptosis, cellular senescence, proliferation, differentiation, and tumorigenesis. Wide research was conducted to establish the role of DNA methylation in development, diagnosis, and prognosis of cancer [8]. The analysis of the whole blood methylation by different methods identified that methylation of many gene loci are related to the risk of breast cancer [9]. There are many well-established environmental and genetic factors associated with breast cancer risk, but whether DNA methylation measured in blood is associated with breast cancer risk or not remains to be determined.

Bodelon et al. [10] reported that the blood DNA methylation might be a reflection to an immunological reaction in the breast tissue or a changed molecular pathway involved in carcinogenesis, or it may be an entity to risk factors like high estrogen level or obesity.

Aging is considered an attributable factor to carcinogenesis [11]. Also, obesity, family history of breast cancer, reproductive factors, and estrogen intake are considered as the most common conditions that predispose to breast cancer; however, breast cancer can be a preventable disease by reducing these risk factors [12].

P14/ARF gene was reported to be aberrantly methylated in the blood of patients with many cancers including colon cancer [13], lung cancer, and leukemia [14]. The results of previous studies about $p 14 / A R F$ methylation in breast cancer were inconsistent. Delmonico et al. [15] suggested that P14/ARF gene was hypermethylated in the impalpable benign and malignant lesions of the breast. A previous study by Barekati et al. [16] reported that p14/ARF methylation in breast cancer tissue was not different from normal tissue. To the best of our knowledge, peripheral methylation of p14/ARF in women at the risk of breast cancer has not been investigated before. Therefore, this study aimed to investigate the influence of non-reproductive and reproductive risk factors of breast cancer on $p 14 / A R F$ methylation to explore the relationship between $p 14 / A R F$ methylation and the risk of breast cancer in healthy females with or without a family history of breast cancer.

\section{Methods}

\section{Subjects}

A total of 120 cancer-free subjects were enrolled in the current study. To show the effect of the non-reproductive risk factors of breast cancer (family history of breast cancer, age, BMI) on the peripheral $p 14 / A R F$ methylation, the healthy cancer-free subjects were classified into groups which had or did not have a risk factor. The family history of breast cancer was defined as a history of breast cancer in one of the first-degree relatives including mother or sister or daughter. They were recruited from the South Egypt Cancer Institute from January 2017 to June 2018 during their attendance with their relatives who diagnosed as breast cancer patients. Also, the healthy females were classified into groups according to the presence or absence of reproductive risk factors (age of menarche, age at fullterm pregnancy, age at menopause, number of children, breastfeeding duration, parity). Exclusion criteria were a prior history of breast cancer or other tumors and age less than 18 years. The study was approved by the Medical Ethics Committee of faculty of medicine, Assiut University (17100649). All subjects provided a written informed consent before the start of the study.

\section{DNA extraction}

DNA was extracted from peripheral blood samples that were taken in tubes containing EDTA anticoagulant. Biospin Whole Blood Genomic DNA Extraction Kit (Gerham Pharmaceuticals, China, Cat\#: BSC06S1) was utilized according to the instructions provided by the manufacturer. A nanodrop spectrophotometer (DNA, RNA calculator nanodrop, Epoch, Bioteck company BMS) was used to measure the DNA concentration.

\section{Sodium bisulfite modification of DNA}

The EZ DNA Methylation-Direct ${ }^{\mathrm{mi}}$ Kit (Zymo Research Corporation, USA, Catalog No. D5020) was used for bisulfite treatment of DNA. The bisulfite treatment method depends on the conversion of the unmethylated cytosine to uracil, and methylated cytosine remains unchanged giving rise to a difference in the sequence between methylated and unmethylated DNA. The process of bisulfite treatment was started by sodium bisulfite reaction with extracted DNA, and denaturation was done in a thermal cycler (Bio-Rad) for about $14 \mathrm{~h}$ and then treatment with m-binding solution, washing, desulphonation, washing, and finally elution with $12 \mu \mathrm{l}$ buffer. For the stability of the converted DNA, it was stored in $-80{ }^{\circ} \mathrm{C}$ and used for methylation-specific-PCR (MSP) within 1 month.

\section{Methylation-specific SYBR green PCR}

Methylation-specific qPCR was done with $2 \mu \mathrm{l}$ of bisulfitetreated DNA, $10 \mu \mathrm{l}$ SensiFAST SYBR Hi-ROX (Bioline, USA, Cat BIO-52067), $1 \mu \mathrm{l}$ of forward, $1 \mu \mathrm{l}$ of reverse primer, and $6 \mu \mathrm{l}$ of bidistilled water. The PCR reaction was performed in 96 well-plate 7500 fast real-time PCR system (Applied Biosystems). The PCR conditions included an activation stage at $95^{\circ} \mathrm{C}$ for $15 \mathrm{~min}, 40$ cycles of denaturation at $95^{\circ} \mathrm{C}$ for $30 \mathrm{~s}$, annealing at $60{ }^{\circ} \mathrm{C}$ for $60 \mathrm{~s}$, and extension at $72{ }^{\circ} \mathrm{C}$ for $60 \mathrm{~s}$. The methylated $p 14 / A R F$ primer used was as follows: forward: $5^{\prime}$-gtgttaaagggcggcgtagc- 3 ', reverse: 5'-aaaaccctcactcgcgacga-3' (Thermofisher scientific, UK). The unmethylated $p 14 / A R F$ primer was used as follows: the forward: $5^{\prime}$-aaaaccctcactcgcgacga- $3{ }^{\prime}$ and the reverse $5^{\prime}$ cacaaaaaccctcactcacaacaa-3' (Thermofisher scientific, UK). The accession number of $p 14 / A R F$ in the gene bank is AF082338.1. 


\section{Calculation of the methylation percentage}

The present study used methylation percentage of $p 14 /$ $A R F$ gene as described in a previous study that established the following equation: $p 14 / A R F$ methylation percentage $=$

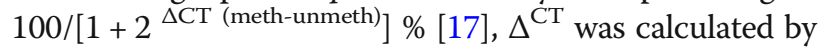
subtracting the $C t$ values of methylated $p 14 / A R F$ signals from the $\mathrm{Ct}$ values of unmethylated $p 14 / A R F$ signals. The $\mathrm{Ct}$ values ranged from 22 to 39 and the mean of $\mathrm{Ct}$ values of methylated $p 14 / A R F$ was higher than the mean of $\mathrm{Ct}$ values of unmethylated $p 14 / A R F$.

\section{Statistical analysis}

IBM SPSS 22 Software was utilized for statistical analysis. Continuous data were presented as means $\pm S D$ while qualitative data were used as a percent and frequency. The normality of the dependent variable ( $p 14$ / $A R F$ methylation percentage) was checked for the independent variables (subgroups) by skewness and kutrosis $z$ values. The chi-square test was used for comparison between the percentages of risk factors (subgroups) between the two groups. The unpaired $t$ test was used for the comparison between the mean of two groups. The correlations between the methylation percentages of $p 14 / A R F$ gene and risk factors were done by use of the Pearson correlation test. Univariate linear regression with method enter was used to show the predicted effects of the breast cancer risk factors on $p 14 / A R F$ methylation. Statistical significances were assumed when the $p$ values were less than 0.05 .

\section{Results}

Characteristics of the studied groups according to the risk factors of breast cancer

Table 1 shows the distribution of the number and the frequencies of subgroups according to the risk factors of breast cancer in the females with and without a family history of breast cancer groups (120 subjects). A total of 100 healthy females was used in the comparison between

Table 1 The distribution of the number and percentages of breast cancer risk factors in females with and without family history of breast cancer

\begin{tabular}{|c|c|c|c|c|}
\hline Breast cancer risk factors (no) & $\begin{array}{l}\text { Females with no family history } \\
\text { of breast cancer no. (\%) }\end{array}$ & $\begin{array}{l}\text { Females with family history } \\
\text { of breast cancer no. (\%) }\end{array}$ & Chi-square & $p$ value \\
\hline \multicolumn{5}{|l|}{ Age } \\
\hline$<40$ years $(60)$ & $30(50)$ & $30(50)$ & 0.018 & 0.895 \\
\hline$\geq 40$ years $(60)$ & $30(50)$ & $30(50)$ & & \\
\hline \multicolumn{5}{|l|}{ Age at full-term Pregnancy (100) } \\
\hline$<25$ years $(88)$ & $44(73.3)$ & $44(73.3)$ & 0.000 & 1 \\
\hline$\geq 25$ years $(12)$ & $6(10)$ & $6(10)$ & & \\
\hline \multicolumn{5}{|l|}{ Age at menarche } \\
\hline$<14$ years $(66)$ & $36(60)$ & $30(50)$ & 1.83 & 0.400 \\
\hline$\geq 14$ years $(54)$ & $24(40)$ & $30(50)$ & & \\
\hline \multicolumn{5}{|l|}{ Menopausal state } \\
\hline Premenopausal (88) & $46(76.7)$ & $42(70)$ & 0.341 & 0.771 \\
\hline Postmenopausal (32) & $14(23.3)$ & $18(30)$ & & \\
\hline \multicolumn{5}{|l|}{ Number of children (100) } \\
\hline 1-2 child (12) & $6(12)$ & $6(12)$ & 0.000 & 1 \\
\hline$>2$ children (88) & $44(88)$ & $44(88)$ & & \\
\hline \multicolumn{5}{|l|}{ Parity } \\
\hline Nulliparous (20) & $10(16.7)$ & $12(20)$ & 0.111 & 0.739 \\
\hline Multiparous (100) & $50(83.3)$ & $48(80)$ & & \\
\hline \multicolumn{5}{|l|}{ \#BMI (116) } \\
\hline $25-29 \mathrm{~kg} / \mathrm{m}^{2}(52)$ & $38(67.9)$ & $14(23.3)$ & 11.06 & $0.001^{* *}$ \\
\hline$\geq 30 \mathrm{~kg} / \mathrm{m}^{2}(64)$ & $18(32.1)$ & $46(76.7)$ & & \\
\hline \multicolumn{5}{|l|}{ Duration of breastfeeding (100) } \\
\hline 6-18 months (50) & $32(66.6)$ & 18 (34.6) & 5.29 & $0.021 *$ \\
\hline 19-24 months (50) & $16(33.3)$ & $34(65.4)$ & & \\
\hline
\end{tabular}

Chi-square test was used to show the difference between the number of subgroups according to the risk factors of breast cancer. A $p$ value was significant if $<$ 0.05. BMl: body mass index. $\neq: 4$ cases were excluded from analysis as their BMI was less than $25 \mathrm{~kg} / \mathrm{m}^{2}$

${ }^{*} p<0.05,{ }^{* *} p<0.01$ 
these subgroups, including the age at full-term pregnancy, number of children, and breastfeeding duration. One hundred sixteen subjects (4 cases were excluded from analysis as their BMI was less than $25 \mathrm{~kg} / \mathrm{m}^{2}$ ) were divided into two subgroups according to BMI; the first subgroup was the overweight with BMI $25-29 \mathrm{~kg} / \mathrm{m}^{2}$, whereas the second subgroup was the obese with BMI $\geq$ $30 \mathrm{~kg} / \mathrm{m}^{2}$. There were no significant differences within the number of subgroups between the two groups as regards to the age, the age at menarche, the age at first full-term pregnancy, the menopausal state, the number of children, and the parity. The frequency of subjects with $\mathrm{BMI} \geq 30 \mathrm{~kg} / \mathrm{m}^{2}$ was significantly higher in females with a family history of breast cancer $(46 / 60,76.7 \%)$ than in females with no family history of breast cancer $(18 / 56$, $32.1 \%),(p=0.001)$. The percentage of subjects with duration of breastfeeding 6-18 months was $66.6 \%$ and $34.6 \%$ in females without and with a family history of breast cancer, respectively, whereas the number of subjects that had duration of breastfeeding for more than 18 months was significantly higher in females with a family history of breast cancer in comparison to females without family history $34 / 52$, (665.4\%) vs 16/48 (33.3\%), $p=0.021$.

\section{Association of $p 14 / A R F$ methylation percentage with the risk factors of breast cancer}

The females with age more than 40 years had a significantly higher $p 14 / A R F$ methylation expression level in comparison to females with age less than 40 years ( $p=$ 0.029 ). There were no significant differences between $p 14 / A R F$ methylation levels among the subdivided subjects according to the family history of breast cancer, BMI, nor the reproductive risk factors (Table 2).

\section{Univariate linear regression analysis of $p 14 / A R F$} methylation percentage according to studied subgroups To investigate the predictors of p14/ARF methylation percentage in healthy females, we used univariate linear regression analysis, the variables assessed were divided to categorical variables (family history, menopausal state, breastfeeding duration, the age, the age at menarche, the age at full-term pregnancy and number of children). The age was independent risk factor to $p 14 / A R F$ methylation $(\beta=1.46, p=0.029)$ as the age above 40 years was associated with an increase of $p 14 / A R F$ methylation. However, neither the family history or reproductive factors of breast cancer were linked to p14/ARF methylation percentage (Table 3).

\section{Correlation of $p 14 / A R F$ methylation percentage with risk factors of breast cancer}

Correlation analysis between p14/ARF methylation percentage and risk factors of breast cancer is illustrated in Table 4. There were positive correlations between the age and $p 14 / A R F$ methylation percentage $(r=0.285, p=$
Table 2 Methylation percentage of p14/ARF gene among the studied subgroups of breast cancer risk factors

\begin{tabular}{|c|c|c|c|}
\hline Parameter $(n)$ & Groups $(n)$ & Means $\pm S D$ & $p$ value \\
\hline \multicolumn{4}{|l|}{ Age (120) } \\
\hline & $<40$ years $(60)$ & $30.31 \pm 1.73$ & \multirow[t]{2}{*}{0.029} \\
\hline & $\geq 40$ years $(60)$ & $31.8 \pm 3.1$ & \\
\hline \multicolumn{4}{|c|}{ Family history (120) } \\
\hline & No (60) & $31.12 \pm 3.17$ & \multirow[t]{2}{*}{0.671} \\
\hline & Yes (60) & $30.83 \pm 1.89$ & \\
\hline \multicolumn{4}{|c|}{ Age at menarche (120) } \\
\hline & < 14 years $(64)$ & $31.02 \pm 2.8$ & \multirow[t]{2}{*}{0.820} \\
\hline & $\geq 14$ years $(56)$ & $30.8 \pm 2.3$ & \\
\hline \multicolumn{4}{|c|}{ Menopausal state (120) } \\
\hline & Premenopausal (88 & $30.75 \pm 2.6$ & \multirow[t]{2}{*}{0.276} \\
\hline & Postmenopausal (32) & $31.6 \pm 2.7$ & \\
\hline \multicolumn{4}{|c|}{ Number of children (100) } \\
\hline & 1-2 children (12) & $31.28 \pm$ & \multirow[t]{2}{*}{0.838} \\
\hline & $>2$ children (88) & $31.03 \pm$ & \\
\hline \multicolumn{4}{|c|}{ Breastfeeding duration (100) } \\
\hline & 6-18 months (50) & $31.45 \pm 2.4$ & \multirow[t]{2}{*}{0.183} \\
\hline & 19-24 months (50) & $30.48 \pm 2.5$ & \\
\hline \multicolumn{4}{|l|}{ BMI (116) } \\
\hline & $25-29 \mathrm{~kg} / \mathrm{m}^{2}(52)$ & $31.4 \pm 3.2$ & \multirow[t]{2}{*}{0.275} \\
\hline & $>30 \mathrm{~kg} / \mathrm{m}^{2}(64)$ & $30.7 \pm 2$ & \\
\hline \multicolumn{4}{|l|}{ Parity (120) } \\
\hline & Nulliparous (20) & $30.5 \pm 1.5$ & \multirow[t]{2}{*}{0.379} \\
\hline & Multiparous (100) & $31.2 \pm 2.7$ & \\
\hline \multicolumn{4}{|c|}{ Age at full-term pregnancy (100) } \\
\hline & $<25$ years $(14)$ & $30.4 \pm 1.8$ & \multirow[t]{2}{*}{0.368} \\
\hline & $>25$ years $(86)$ & $31.14 \pm 2.8$ & \\
\hline
\end{tabular}

The continuous data were expressed as means \pm SD. Independent sample $t$ test showed the difference of $p 14 / A R F$ methylation percentage between the subgroups. BMI: body mass index. $P$ value is significant if less than 0.05

0.014). In addition, reproductive factors as age at menarche, number of pregnancies, age at first childbirth, and breastfeeding duration were not correlated with the quantitative methylation expression level of $p 14 /$ $A R F$ gene.

\section{The distribution of the low and high methylation expression levels of $p 14 / A R F$ according to the age subgroups}

The median of $p 14 / A R F$ methylation percentage was $30.03 \%$, so the studied subjects were classified into two groups, low and high methylation of $p 14 / A R F$. The percentage of females with age more than 40 years who had high $p 14 / A R F$ methylation were insignificantly higher than those with low $p 14 / A R F$ methylation $(p=0.088)$. Also, low 
Table 3 Univariate linear regression analysis of the association of p14/ARF methylation percentage with breast cancer risk factors

\begin{tabular}{|c|c|c|c|c|}
\hline Parameter & Regression coefficient $\beta$ & Standard error & $t$ test & $p$ \\
\hline Constant & -75.13 & 43.14 & -0.175 & 0.088 \\
\hline Age & 1.46 & 0.65 & 2.24 & 0.029 \\
\hline BMl & -0.397 & 0.597 & -0.66 & 0.512 \\
\hline Age at menarche & 0.083 & 0.255 & 0.326 & 0.745 \\
\hline Number of children & -0.249 & 1.21 & -0.206 & 0.838 \\
\hline Age at first childbirth & -3.05 & 1.84 & -1.66 & 0.104 \\
\hline Parity & 0.542 & 0.86 & 0.62 & 0.54 \\
\hline Breastfeeding duration & -0.973 & 0.726 & -1.34 & 0.187 \\
\hline Family history & 0.288 & 0.674 & -0.427 & 0.671 \\
\hline Menopausal state & 8.42 & 0.755 & 1.11 & 0.270 \\
\hline
\end{tabular}

Univariate linear regression was used to demonstrate the independent effect of risk factors (expressed as categorical values) on the $p 14 / A R F$ methylation percentage (dependent factor) with the enter method. $P$ value is significant if less than 0.05

$p 14 / A R F$ methylation was more found distributed in younger women, less than 40 years, Table 5 .

\section{Discussion}

DNA transformation and epigenetic alterations can be recognized in each of breast tissue and blood of healthy females with a positive history of breast cancer in their relatives [18]. Furthermore, aberrant DNA methylation is as well as a hazardous factor for breast malignant growth, but also it is an increment agent to the conceptual elements of breast carcinogenesis [19]. It is accepted that incident breast carcinoma increased with age that co-occurs with DNA methylation conducting to carcinogenesis [20]. Hence, the identification of the interactions of DNA methylation with reproductive and non-reproductive risk factors for breast cancer is a fundamental issue in breast cancer research.

The present study explored the association of $p 14 / A R F$ methylation with the risk factors of breast cancer in 60 healthy females with a family history of breast cancer and another 60 females with no family history of breast cancer. Curiously, $p 14 / A R F$ methylation percentage in the current study was not associated with a family history of breast cancer. As far as we could know, there are no studies about p14/ARF methylation and family history of breast cancer in hazardous women was reported, and our results are a preliminary report and enormous planned investigations are needed. Previously, $p 14 / A R F$ methylation studies reported that to be not linked to the cancer family history in Indian breast cancer patients [21], and Egyptian colorectal cancer patients [13], however, change in DNA methylation due to a family history of breast cancer had been confirmed by several studies. Scott et al. [22] investigated blood DNA methylation in Australian women with BRCA1-like earlyonset breast cancer and indicated that higher methylation of $B R C A-1$ promoter in those women than non-BRCA mutation carrier women. Recently, Joo et al. [23] identified 24 heritable DNA methylation markers in the blood of 210 Australian females by Infinium Human Methylation 450, five of these 24 were present in the promoter region of a vault RNA, VTRNA2-1 and the remaining 19 were distributed differently in the genome.

In the present study, reproductive risk factors of breast cancer were not associated with $p 14 / A R F$ methylation percentage as indicated by independent $t$ test and univariate analysis. Our data cannot be compared with other studies because different methods of estimation of $p 14 / A R F$ methylation, and no methylation studies linked $p 14 / A R F$ to the reproductive factors of breast cancer in cancer-free females. Further studies are needed, but we suggest that $p 14 / A R F$ methylation in the previous studies were associated with reproductive risk factors of breast cancer [24] due to the correlation of breast tissue DNA methylation with blood DNA methylation, so $p 14 / A R F$ hypermethylation may only occur in the presence of breast cancer. On the contrary, a previous web study showed that the risk factors of breast cancer in breast cancer patients were not related to any of the CDKN2A genes (p14/ARF, p16) [25].

An explanation of the present results that showed no association of $p 14 / A R F$ methylation with breast cancer risk factors is the small sample size of the present study.

Table 4 Correlation of p14/ARF methylation percentage with breast cancer risk factors

\begin{tabular}{lllllllll}
\hline Parameter & Age & BMI & $\begin{array}{l}\text { Age at } \\
\text { menarche }\end{array}$ & $\begin{array}{l}\text { Number } \\
\text { of children }\end{array}$ & $\begin{array}{l}\text { Age at first } \\
\text { childbirth }\end{array}$ & $\begin{array}{l}\text { Parity } \\
\text { Breastfeeding }\end{array}$ & $\begin{array}{l}\text { Family history } \\
\text { Duration }\end{array}$ & $\begin{array}{l}\text { Menopausal } \\
\text { state group }\end{array}$ \\
\hline$r$ & 0.285 & -0.068 & 0.043 & -0.030 & 0.303 & 0.082 & -0.194 & 0.145 \\
$p$ & 0.014 & 0.256 & 0.373 & 0.417 & 0.160 & 0.682 & 0.093 & 0.336 \\
\hline
\end{tabular}

r: Correlation by Pearson correlation test obtained during univariate analysis. BMI: body mass index. $P$ value is signficant if less than 0.05 
Table 5 Distribution of low and high p14/ARF methylation in the age subgroups

\begin{tabular}{llll}
\hline Age in years & Low p14/ARF methylation expression (72) & $\begin{array}{l}\text { High p14/ARF methylation expression (48) } \\
n(\%)\end{array}$ & Chi-square \\
\hline Age $<40$ years (60) & $42(70 \%)$ & $18(30 \%)$ & 2.88 \\
Age $>40$ years (60) & $30(50 \%)$ & $30(50 \%)$ & 0.088 \\
\hline
\end{tabular}

The incompatibility of results of previous research on the $p 14 / A R F$ gene methylation and breast cancer needs to be mentioned. One of these studies had shown a link between $p 14 / A R F$ methylation and breast cancer in both young and old women [26]. On the contrary, there was no difference between the normal and carcinogenic tissue of the breast concerning $p 14 / A R F$ methylation $[27,28]$. Compared to other genes as $p 16$ and $A T M$, the $p 14 / A R F$ gene showed a relatively small percentage of the methylation in breast tissue, blood, and saliva from breast cancer patients with impalpable lesions.

The relationship between $p 14 / A R F$ methylation and the risk factors of breast cancer in healthy women had not been studied before. Our results might be an extension of the previous studies that reported that the relation of p14/ARF methylation to the breast cancer risk factors in breast cancer patients is insubstantial, and the present gene is scarcely affected by methylation on account of breast cancer risk factors. The interplay of DNA methylation and breast cancer risk factors on the odds of breast cancer were investigated by other researchers. For example, one of the researchers, Collin et al. [19] studied the effect of reproductive factors on peripheral global methylation in a population-based study and the authors suggested that age at menarche and age at first birth may be modifiers of the association between global DNA methylation and breast cancer risk.

In the present study, $p 14 / A R F$ methylation percentage was significantly higher in females aged above 40 years than females aged less 40 years. Also, a positive correlation between $p 14 / A R F$ methylation and the age was detected. Univariate analysis revealed that age is an independent factor of the $p 14 / A R F$ methylation percentage. The age is the most important factor for breast cancer susceptibility and $p 14 / A R F$ methylation was significantly higher in breast cancer patients older than 50 years as showed by a study of Askari et al. [21], but the authors also revealed that the $p 14 / A R F$ methylation percentage was insignificant between menopause, age at menarche, or age at full-term pregnancy subgroups as shown in the current report. Interestingly, $p 14 / A R F$ methylation frequency was insignificantly higher with age of menarche, age at menopause above 50 years in breast cancer patients [21]. According to previous studies, the DNA methylation changes that arise due to aging occur at specific loci [29] and may be affected by the BMI [30]. Moreover, the rarely detectable DNA methylation in normal tissues is attributed to aging [31], and these epigenetic alterations in aged subjects may initiate carcinogenesis [11]. An increase of p14/ARF methylation percentage by age might indicate the loss of the regenerative power of the cells and susceptibility to malignancy.

There are some limitations to this study, including the small number of patients studied and the lack of p14/ARF gene methylation study in breast cancer patients at the same time with healthy females. Also, patients with more than one relative with breast cancer were not studied, and the effect of several risk factors was not discussed together.

\section{Conclusion}

The present study suggests that the relationship of $p 14 /$ $A R F$ methylation with the reproductive risk factors of breast cancer in healthy females is delicate, and p14/ARF methylation percentage is only associated with the age as one of the non-reproductive risk factors of breast cancer. The present study gives an illusion about relationships of $p 14 / A R F$ methylation with risk factors of breast cancer in breast cancer-free females; however, further large studies are needed for approving this association.

\section{Abbreviations}

ARF: Alternative reading frame; BMI: Body mass index; CDK: Cyclindependent kinase; CDKN2A/INK4A: Cyclin-dependent kinase inhibitor 2A/ inhibitor of cyclin-D4; HIF1: Hypoxia-inducible factor1; MDM2: E3 ubiquitin ligase; MSP: Methylation-specific PCR; NPM: Nucleophosmin (nucleolar phosphoprotein B23)or numatrin; P53: Tumor protein53; Tip60: Tat-interactive protein, $60 \mathrm{kDa}$

\section{Acknowledgements}

Not applicable.

\section{Authors' contributions}

ME interpreted the subject's data regarding the risk factors of breast cancer. GE performed the laboratory work and was a major contributor in writing the manuscript and statistical analysis. Both authors read and approved the final manuscript.

\section{Funding}

This article was funded by the authors.

\section{Availability of data and materials}

All data generated or analyzed during this study are included in this published article and its supplementary information files.

Ethics approval and consent to participate

The study was approved by the Medical Ethics Committee of the Faculty of Medicine, Assiut University (17100649). Written informed consent was obtained from all the participants in this study.

Consent for publication

Not applicable. 


\section{Competing interests}

The authors declare that they have no competing interests.

\section{Author details}

'Department of Medical Biochemistry, Faculty of Medicine, Assiut University, Assiut 75151, Egypt. ${ }^{2}$ Surgical Oncology Department, South Egypt Cancer Institute, Assiut University, Assiut 75151, Egypt.

\section{Received: 2 July 2019 Accepted: 21 September 2019}

Published online: 12 November 2019

\section{References}

1. Williams RT, Barnhill LM, Kuo HH, Lin WD, Batova A, Yu AL et al (2014) Chimeras of p14ARF and p16: functional hybrids with the ability to arrest growth. PLoS One 9(2):e88219

2. Wadhwa R, Sugihara T, Taira K, Kaul SC (2004) The ARF-p53 senescence pathway in mouse and human cells. Histol Histopathol 19(1):311-316

3. Ko A, Han SY, Song J (2018) Regulatory network of ARF in cancer development. Mol Cells 41(5):381-389

4. Cui L, Zhou F, Chen C, Wang CC (2019) Overexpression of CCDC69 activates p14(ARF)/MDM2/p53 pathway and confers cisplatin sensitivity. J Ovarian Res 12(1):4

5. Lutful Kabir FM, Agarwal P, Deinnocentes P, Zaman J, Bird AC, Bird RC (2013) Novel frameshift mutation in the p16/INK4A tumor suppressor gene in canine breast cancer alters expression from the p16/INK4A/p14ARF locus. J Cell Biochem 114(1):56-66

6. Tsujimoto $H$, Hagiwara A, Sugihara H, Hattori T, Yamagishi H (2002) Promoter methylations of p16INK4a and p14ARF genes in early and advanced gastric cancer. Correlations of the modes of their occurrence with histologic type. Pathol Res Pract 198(12):785-794

7. Bogdanovic O, Lister R (2017) DNA methylation and the preservation of cell identity. Curr Opin Genet Dev 46:9-14

8. Pan Y, Liu G, Zhou F, Su B, Li Y (2018) DNA methylation profiles in cancer diagnosis and therapeutics. Clin Exp Med 18(1):1-14

9. Yang Y, Wu L, Shu XO, Cai Q, Shu X, Li B et al (2019) Genetically predicted levels of DNA methylation biomarkers and breast cancer risk: data from 228,951 women of European descent. J Natl Cancer Inst. 2019. https://doi. org/10.1093/jnci/djz109. [Epub ahead of print].

10. Bodelon C, Ambatipudi S, Dugué P-A, Johansson A, Sampson JN, Hicks B et al (2019) Blood DNA methylation and breast cancer risk: a meta-analysis of four prospective cohort studies. Breast Cancer Res 21(1):62

11. Licher S, Heshmatollah A, van der Willik KD, Stricker BHC, Ruiter R, de Roos EW et al (2019) Lifetime risk and multimorbidity of non-communicable diseases and disease-free life expectancy in the general population: a population-based cohort study. PLoS Med 16(2):e1002741

12. Sun YS, Zhao Z, Yang ZN, Xu F, Lu HJ, Zhu ZY et al (2017) Risk factors and preventions of breast cancer. Int J Biol Sci 13(11):1387-1397

13. Salama RH, Sayed ZEA, Ashmawy AM, Elsewify WA, Ezzat GM, Mahmoud MA et al (2019) Interrelations of apoptotic and cellular senescence genes methylation in inflammatory bowel disease subtypes and colorectal carcinoma in Egyptians patients. Appl Biochem Biotechnol 189(1):330-343.

14. Zemliakova W, Strel'nikov W, Zborovskaia IB, Balukova OV, Maiorova OA, Vasil'ev EV et al (2004) Abnormal methylation of p16/CDKN2A and p14/ARF genes GpG Islands in non-small cell lung cancer and in acute lymphoblastic leukemia. Mol Biol 38(6):966-972

15. Delmonico L, Moreira Ados S, Franco MF, Esteves EB, Scherrer L, Gallo CV, et al (2015) CDKN2A (p14(ARF)/p16(INK4a) and ATM promoter methylation in patients with impalpable breast lesions. Hum Pathol 46(10):1540-1547

16. Barekati Z, Radpour R, Kohler C, Zhang B, Toniolo P, Lenner P et al (2010) Methylation profile of TP53 regulatory pathway and mtDNA alterations in breast cancer patients lacking TP53 mutations. Hum Mol Genet 19(15):2936-2946

17. Ng EK, Leung CP, Shin WY, Wong CL, Ma ES, Jin HC et al (2011) Quantitative analysis and diagnostic significance of methylated SLC19A3 DNA in the plasma of breast and gastric cancer patients. PLoS One 6(7):e22233

18. Evans DG, Astley S, Stavrinos P, Harkness E, Donnelly LS, Dawe S, Jacob I, Harvie M, Cuzick J, Brentnall A, Wilson M, Harrison F, Payne K, Howell A (2016). Source improvement in risk prediction, early detection and prevention of breast cancer in the NHS breast screening programme and family history clinics: a dual cohort study.Southampton (UK): NIHR Journals Library; 2016 Aug.

19. Collin L, McCullough LE, Conway K, White AJ, Xu X, Cho YH et al (2019) Reproductive characteristics modify the association between global DNA methylation and breast cancer risk in a population-based sample of women. PLoS One 14(2):e0210884

20. Barajas-Gomez BA, Rosas-Carrasco O, Morales-Rosales SL, Pedraza Vazquez G, Gonzalez-Puertos WY, Juarez-Cedillo T et al (2017) Relationship of inflammatory profile of elderly patients serum and senescence-associated secretory phenotype with human breast cancer cells proliferation: role of IL6/L8 ratio. Cytokine. 91:13-29

21. Askari M, Sobti RC, Nikbakht M, Sharma SC (2013) Promoter hypermethylation of tumour suppressor genes (p14/ARF and p16/INK4a): case-control study in north Indian population. Mol Biol Rep 40(8):4921-4928

22. Scott CM, Wong EM, Joo JE, Dugue PA, Jung CH, O'Callaghan N et al (2018) Genome-wide DNA methylation assessment of 'BRCA1-like' early-onset breast cancer: data from the Australian breast cancer family registry. Exp Mol Pathol 105(3):404-410

23. Joo JE, Dowty JG, Milne RL, Wong EM, Dugue PA, English D et al (2018) Heritable DNA methylation marks associated with susceptibility to breast cancer. Nat Commun 9(1):867

24. Sharma G, Mirza S, Prasad CP, Srivastava A, Gupta SD, Ralhan R (2007) Promoter hypermethylation of p16INK4A, p14ARF, CyclinD2 and Slit2 in serum and tumor DNA from breast cancer patients. Life Sci 80(20):1873-1881

25. George A (2018). Altered breast tumor DNA methylation: associations with participant parity and lactation in the Western New York exposures and breast Cancer (WEB) study: State University of New York at Buffalo.ubir. buffalo.edu. www.googlescholar.com.

26. Sinha S, Chunder N, Mukherjee N, Alam N, Roy A, Roychoudhury S et al (2008) Frequent deletion and methylation in SH3GL2 and CDKN2A loci are associated with early- and late-onset breast carcinoma. Ann Surg Oncol 15(4):1070-1080

27. Barekati Z, Radpour R, Lu Q, Bitzer J, Zheng H, Toniolo P et al (2012) Methylation signature of lymph node metastases in breast cancer patients. BMC Cancer 12:244

28. Zemliakova W, Zhevlova Al, Strel'nikov W, Liubchenko LN, Vishnevskaia la V, Tret'iakova VA et al (2003) Abnormal methylation of several tumor suppressor genes in sporadic breast cancer. Mol Biol 37(4):696-703

29. Horvath S (2013) DNA methylation age of human tissues and cell types. Genome Biol 14(10):R115

30. Garagnani P, Bacalini MG, Pirazzini C, Gori D, Giuliani C, Mari D et al (2012) Methylation of ELOVL2 gene as a new epigenetic marker of age. Aging Cell 11(6):1132-1134

31. Kang WS, Cho SB, Park JS, Lee MY, Myung SC, Kim WY et al (2013) Clinicoepigenetic combination including quantitative methylation value of DKK3 augments survival prediction of the patient with cervical cancer. J Cancer Res Clin Oncol 139(1):97-106

\section{Publisher's Note}

Springer Nature remains neutral with regard to jurisdictional claims in published maps and institutional affiliations.

\section{Submit your manuscript to a SpringerOpen ${ }^{\circ}$ journal and benefit from:}

- Convenient online submission

- Rigorous peer review

- Open access: articles freely available online

- High visibility within the field

- Retaining the copyright to your article

Submit your next manuscript at $>$ springeropen.com 